\title{
Demonstrating the potential of Regional Ocean Model System in simulating the upper ocean characteristic over Arabian Sea: impact of horizontal resolution
}

\section{Prabha Kushwaha}

University of Allahabad

Vivek Kumar Pandey ( $\sim$ vivekbhuoa@gmail.com )

University of Allahabad https://orcid.org/0000-0003-1534-0238

\section{Research Article}

Keywords: ROMS, Monsoon, Arabian Sea, SST, SSS, Resolution

Posted Date: August 9th, 2021

DOl: https://doi.org/10.21203/rs.3.rs-792515/v1

License: (c) (1) This work is licensed under a Creative Commons Attribution 4.0 International License. Read Full License

Version of Record: A version of this preprint was published at Theoretical and Applied Climatology on January 31st, 2022. See the published version at https://doi.org/10.1007/s00704-022-03934-8. 


\section{Abstract}

This study attempted to demonstrate the skill of the regional ocean model system (ROMS) is simulating the hydrographic property of the Arabian Sea (AS). Additionally, the impact of horizontal resolution is investigated. In this regard, ROMS is integrated over AS covering $\left[30^{\circ} \mathrm{E}-80^{\circ} \mathrm{E} ; 5^{\circ} \mathrm{N}-30 \mathrm{~N}^{\circ}\right]$ at two different horizontal resolutions $1 / 6^{\circ}(\sim 17 \mathrm{~km})$ and $1 / 4^{\circ}(\sim 25 \mathrm{~km})$ for ten years. The comparison of model results with available observation and reanalysis indicates reasonable resemblances in reproducing the spatialtemporal distribution of surface and subsurface hydrographic property i.e. sea surface temperature (SST), sea surface salinity (SSS), sea surface currents, and subsurface temperature and salinity at both resolutions. The increasing resolution shows minimal improvement, indicating the fact that its not always guaranty to enhance the performance towards increasing resolution for every aspect.

\section{Introduction}

The Arabian Sea (AS) is an oceanic basin which is enclosed by the northwestern tropical Indian Ocean and it's variability plays an important role in Indian summer monsoon rainfall (Pathak et al., 2017; Wang, 2006). Thus, the AS comes in contact with unique geographic featuresforced by strong seasonally reversing monsoon winds (Tomczak andGodfrey 1994). The AS has major oceanic factors like sea surface temperature (SST), sea surface salinity (SSS), and sea surface current (SSC) which are influenced the AS variability and it's remote effect onthemonsoon. The western boundary of the ASSST is cooler (approx $22^{\circ} \mathrm{C}$ ) because of coastal upwelling and large-scale air-sea heat loss (Schott \& McCreary, 2001), while in the east and southeast boundary of the AS SSTs are warmer (approx $28^{\circ} \mathrm{C}$ ) which develops a mini warm pool or warm pool(Neema et al., 2012; Rao et al., 2014; Vinayachandran et al., 2007; Joseph et al., 1990).SSS variability in the tropical Indian Ocean has been studied by using an ocean general circulation model (OGCM) (Sharma et al., 2007,2010,2012). The AS water masses are created by surface processes and ocean-atmosphere interactions with specific temperature and salinity at a specific location (Joseph et al., 2005).TheAS variability and associated mechanisms have been studied by many authors (Kumar and Prasad, 1999; Beal et al., 2000; Prasad and Ikeda, 2002a, 2002b; Stramma et al., 2002). Moreover, few of the authors (Kumar and Prasad, 1999; Prasad and Ikeda, 2002a, 2002b) examined the variability and formation processes based on Climatology and modeling. Many author identify two water masses in the AS known as the Arabian Sea High Salinity Water Mass (ASHSW) and Arabian Sea Water (ASW).In the AS surface water masses with salinity $S 35.5<S<36.5, \theta>22^{\circ} \mathrm{C}$ defined by Donguy and Meyers (1996) as ASW. Morrison (1997) had studied that the ASW as the water mass with a salinity maximum at a density of $25.0 \mathrm{~kg} \mathrm{~m}^{3}$. The west India coastal current (WICC) flows pole-ward during winter monsoon (November to February) and equatorward during the summer monsoon (June to September) (Shetye et al. 1991). WICC carries high salinity waters from the northern Arabian Sea towards the south along the shelf-slope regions in summer (Prasanna Kumar et al. 2004). During thesummer monsoon, the coastal upwelling, occurring in the South Eastern Arabian Sea (Wyrtki 1971) develops primary productivity well on the other side of the shelf-slope regions of peninsular India and SriLanka (Smitha et al. 2008). The South Eastern Arabian Sea is characterized by the occurrence of 
thermal inversion during the winter season (Thadathil and Gosh 1992; Durand et al. 2004; Kurian and Vinayachandran 2006), while under the influence of winter convection of north Eastern Arabian Sea it leads to winter blooms (Madhupratap et al. 1996; Prasanna Kumar and Prasad 1996). SST, feeds back on the winds (Vecchi et al. 2004) causes the abandon rainfall over India (Izumo et al. 2008). In the past, AS has been undertaken three coordinated observing efforts (1960s: International Indian Ocean Expedition; 1970s: Indian Ocean Experiment; and 1990s: World Ocean Circulation Experiment/Joint Global Ocean Flux Study)largely focusing on the southwest monsoon circulation and the western boundary.

Understanding of the AS variability and circulation is incomplete because of limited studies on the availability of the high-resolution data of the oceanic variables. The availability of climatology data is also important for the estimation of the dynamics of ocean variables like SST,SSS, and SSC. The biological production and source-sink of carboncontaining gases are very important for correct knowledge of oceanographic features (Bates 2006a,b). The monsoon circulation in the Indian Ocean a high-resolution $\sigma$-coordinate ocean model studied by (Diansky et al., 2006).Kunal Chakraborty et al., (2019) used a regional ocean model system (ROMS) to provide a simulated result of the upper-ocean biogeochemistry of the AS from an operational perspective. The eddypermitting ocean model for the Indian Ocean towards the Simulation of surface and subsurface variables are studied (Masumoto et al. (2008) and George et al. 2010). Momin et al., 2014 have discussed for higher horizontal resolution in their Indian Ocean intercomparison study, though their model resolution was still too coarse. Similarly, the ocean models with higher horizontal resolution in the better simulation of the Bay of Bengal(BoB) circulation have been studied (Vinyachandran et al., 1996). Therefore, highresolution studies have focused on the evolution of SST, SSS, and SSC for understanding the surface and subsurface hydrography and circulation of AS over a longer duration of time (climatology). Seasonal variability of the AS and its relation to monsoonal current has not been simulated in detail using two different high resolution climatology model data. In the present study, we attempted to demonstrate the skill of ROMS in simulating the hydrographic characteristic of AS. Additionaly, the impact of increasing horizontal resolution is also investigated.

\section{Data And Methods}

\subsubsection{Datasets}

For validation with observations, Remote Sensing Systems datasets are used for SST from TMI datasets(www.remss.com)and climatology of temperature and salinity from WOA-2009(Locarnini, et al., 2013) are used comparison with model outputs. The European Centre for Medium-Range Weather Forecasts (ECMWF) ORS4 datasets is used to validate SSS. Ocean reanalysis data from Simple Ocean Data Assimilation Version 2.2.4(SODA, Carton \& Giese, 2008) for SSC from the same period is used. For comparison with the sub-surface temperature and salinity corresponding, North Indian Ocean Atlas (NIOA) datasets are used.

\subsubsection{Model description}


We adopted Regional Ocean Modeling System (ROMS) version 3.7 (Haidvogel et al. 2008; Shchepetkin and McWilliams 2003, 2005; Penven et al. 2006) forinvestigating the impact of horizontal resolution in simulating AS characteristics. In this regards, ROMS is configured over AS covering $\left(32^{\circ} \mathrm{E}\right.$ to $80^{\circ} \mathrm{E}$ and $5^{\circ} \mathrm{S}$ to $33^{\circ} \mathrm{N}$ ) (figure 1). The ROMS is a three-dimensional, free-surface, terrain-following model that solves the primitive equations based on the Boussinesq approximation and hydrostatic vertical momentum balance in an Earth-centered rotating environment. We used off the shelf with a $5000 \mathrm{~m}$ bottom depth, vertical resolution ranged from $15 \mathrm{~m}$ at the surface to $500 \mathrm{~m}$ at the bottom. The model topography is based on Etopo2 bathymetry (Sindhu et al. 2007). For parameterization, we used K-Profile parameterization vertical mixing scheme (Large et al. 1994). The oceanic boundaries at the eastern, southern, and western edges are closed andthenorthern edge isclosed of the model domain. However, the closed boundary conditions for the climatological variables because of the unavailability of sufficient observations along these boundaries. The temperature and salinity fields are initially at rest taken from the World Ocean Atlas 2009 data set (WOA09, Antonov et al., 2010; Locarnini et al., 2010) at $1^{\circ}$ resolution, in January (beginning of the simulation). We use climatological forcing to investigate the annual and seasonal variability of the Arabian Sea. The models are forced using climatological ocean winds stress derived from climatological of ocean winds (SCOW) data set [Risien and Chelton, 2008], computed on 120 months (Jan 1999 to Dec 2008) of QuickSCATScatterometer data with a resolution of $1 / 4^{\circ}$. Lateral boundary conditions are used for temperature and salinity. Then the climatological run was carried out for the model set-up. The model initial conditions derivedclimatological monthly forcing fields. The forcing fields are implyingtemperature, salinity, zonal wind, meridional wind and air density were used from the $0.5^{\circ}$ monthly climatology of the Comprehensive Ocean-Atmosphere Data Set (COADS) (da Silva et al., 1994). Both the model set-ups are spin for a period of 5 years from the initial state. Bulk parameterizations internally calculated surface heat and momentum fluxes by using ROMS simulation of Liu et al. (1979)and Fairall, Bradley, Godfrey, et al. (1996); Fairall, Bradley, Rogers, et al. (1996). We performed two simulations for 10 years excluding a spinup 5 years. We use 32 terrain-following vertical $\sigma$ layers in all simulations. Both simulations were performed at different horizontal resolutions; $1 / 4^{\circ}(\sim 25 \mathrm{~km})$ and $1 / 6^{\circ}(\sim 17 \mathrm{~km})$ keeping all set up similar.The simulation of the model was carried out for fifteen years, starting from the WOA 2009climatology and the same current. The kinetic energy, temperatureand salinity simulated from both resolution models reach dynamic equilibrium within the first five years. An improved resolution was allocated towards the surface by defining the stretching parameters $\theta \mathrm{s}=7.0$ and $\theta b=0.1$.

\section{Results And Discussion}

We have demonstrated the model's skill for the seasonal and annual cycle of temperature, salinity, and sea surface currentwith the observations.Apart from this, we also evaluated the subsurface temperature, salinity and mixed layer depth. We began with assessing the capability of the model towards capturing the spatial distribution of SST. Figure 2 reapresents the seasonal mean of SST from TMI and both simulations (ROMS-1/4 and ROMS-1/6) duringthe study period. The time-averaged for the study period is considered as annual mean and seasonal averages are obtained for two monsoonal seasons (i) summer (June-September ; JJAS) and (ii) winter (November-February ; NDJF). The model shows reasonable skill in 
simulating the spatial evolution of SST variability in the seasonal and annual scale in the AS (Figure 2). In general higher, SST is noticed over the eastern equatorial region of AS which shows decreasing tendency poleward and westward during winter. In contrast to this, the poleward increasing tendency is noticed. These features are captured in both simulations which is consistent with the previous studies (Rao and Sivakumar 2000; Shenoi et al. 2002; Prasad 2004; Dwivedi et al. 2019). The spatial evolution of the seasonal cycle of the AS SST as observed in TMI-SST is reasonably captured by both models (Figure 2). The highest SST is obtained during the Monsoon months of JJASandthe lowest SST during the winter months of NDJF.

Monsoon season shows warming near the coast due to solar radiation from June to September and the winter season show cooling due to less solar radiation from November to February. The solar radiation continues to increase the SST and strong wind causes a decrease in SST from June to August and low wind speed in September allows the SST to increase again until November. Analysis of the climatology of SST data during the months between June to September shows that SST increases from southeast to northwest and from November to February show that SST increases from northwest to southeast. The model simulation result is not reasonably good in comparison to the observed results. Therefore, SST is required to assess its impact on regional weather and climate system that affects the socioeconomic system.

The annual and seasonal mean of SSS from ECMWF-ORS4 and both simulation ( ROMS-1/4 and ROMS$1 / 6$ ) is shown in Figure 3 . It is clearly represent that the AS salinity vary intherange between 33 PSU to 37 PSU. The time-averaged for the study period is considered as annual mean and seasonal averages are obtained for two monsoonal season one is summer (JJAS) and second one is winter (NDJF). The model shows resultof spatial evolution of SSS variability in the annual and seasonal scale in the AS (figure 3). Comparison of observation and model are simulated are estimated and found that the upper ocean got more saline water. The highest SSS is 36.5 PSU nearthenorthern part of AS and results are valuable for the AS variability. In the southern AS, the lowest SSS during NDJF which may be due to coastal runoff, and also due to movement of less saline BoB water towards AS and its mixing with the saltier AS water (Dwivediet al., 2019).The Arabian SSS is more than 35 PSU throughout the year. During the summer monsoon season SSSincreases in the central AS due to high evaporation and vertical mixing of the surface waters with subsurface high saline waters and during winter monsoon seasonSSS is decreased in the southwest to northeast due to low evaporation in the AS. Annual analysis of SSS is better and gives reasonable results over the AS. ASHSWhas low salinity waters of southern origin can be advected into the region by the Somali and North Equatorial Current (Morrison, 1997). The waters that upwell along the Arabian coast can have salinities resulting from poleward advection associated with the Somali current during the southwest monsoon period (Morrison 1997). In the eastern AS contribute to the formation locally of low salinity waters due to precipitation and runoff from rivers, which in turn augment the subsurface maximum, the identifying feature of the ASHSW. During winter monsoon, the cold and dry winter winds from Asia, combined with Ekman pumping, Cause subduction of high salinity surface waters of the northern AS (Morrison, 1997; Schott and Fischer, 2000). This causes a widespread formation of ASHSW with a salinity maximum just beneath the mixed layer at of 25m (Morrison, 1997). 
Figure 4 represents the bias (Model - observation) for both the simulationsfor JJASmean(upper panel) and NDJF mean (lower panel). The figure indicates the contrasting nature of the bias pattern during JJAS and NDJF. For example, during the JJAS season, high positive SST bias is observed near the south western coast of and negative bias over the northernmost part of AS in both simulation. The reverse is observed during NDJF over central AS. Insignificant bias (within the range of its standard deviation) is observed. This bias pattern is more or less similar in both simulation, however, the magnitude of the bias is slightly lesser in the high-resolution simulation, indicating the advantage of a high resolution. The SST biases are the common problem in most of the model including ROMS simulation (Large et al., 2006) which may be possible the absence of the feedback between different components of the earth system ( Cai et al., 2011; Mishra et al. 2021a,b). Therefore, understanding the origins of SST bias and coupling of the atmospheric component is important to improve the model simulations. During JJAS, ROMS was found to have a cold bias in SST over the northern AS, which might be partially linked with the stronger wind (stronger mixing) due to the absence of negative feedback in the standalone model. During the summer season, this warm SST bias attributed to the anomalous warm winds from the south-eastern part of the south Asian landmass. During the winter season, this warm bias SST bias was attributed to the anomalous warm winds from the northern part of the South Asian landmass. The high-resolution run has reasonably reduced the SST bias in both seasons over the Arabian Sea. Thesmall bias with respect to TMI in southern AS except in the northern AS during the JJAS month. The high SST bias with respect to TMI in the northern AS except in the southern AS. The bias shown along the coasts, it may be ignored since TMI has known problems along the coasts (Wang et al., 2011; Dwivedi et Al. 2019).

Figure 4 represents the SSS bias between Model and SODA SSS for JJAS month (upper panel) and SSS bias between Model and SODA SSS for NDJF month (lower panel).SSS is an key ocean variablefollowed by SST to demonstrate the model performance that is determine by thedynamical component of ocean (circulation) and freshwater transport. Salinity water transport is affected by seasonal variation of current that is monsoonal winds.During the summer season, SSS bias represents the negative bias values above the equator and zero bias all over the AS. Thus, the weaker Somali jet during summer results for reduced positive salt tendency in the central and eastern part of AS. Weak horizontal advection associated over the southeastern AS with east Indian coastal bias during winter limits the formation of spring freshwater pool. Duringthewinter season, SSS bias is better than the summer season. This season shows bias reasonable values over the AS. In the lowresolution, SSS bias shows high SSS bias values against comparison with highresolution SSS bias. Thus major SSS biases in JJAS are seen over the eastern AS (-0.6 -1 psu) and in NDJF biases are noted in northern AS ( 0.5- 1psu). The formation of warm pools in south-eastern ASduring spring is due to freshwater transport associated with East Indian coastal current (EICC) reported by many studies (Durand et al. 2007).

The SST anomaly means a departure from an annual value or long-term average. The positive anomaly indicates anomalously warm conditions while the negative value indicates. Therefore, figure 6 , shows that both simulations bear close resemblance with observation in reproducing the spatio-temporal pattern of the SST anomaly. For example, the warm(cold) anomaly over northern AS(south-eastern coast) during JJAS and reverse is observed during NDJF. The features associated with the SST anomaly have been 
postulated in the several studies (viz. Saha, 1970a, b, 1974) at have warmer SST anomalies in consequence of weaker winds, lesser turbulent mixing and high evaporation. Colder SST anomalies might be caused weak evaporation and stronger wind (higher mixing).

Figure 7 represents the SSS anomaly for the summer season shown in the upper panel and the SSS anomaly for the winter season shown in the lower panel. The importance of SSS anomalies are linking with the global hydrological cycle and Ocean anomalies have been well understood and addressed (Largerloef et al. 2002). The seasonality of SSS anomaly variability similar to mean analyses are performed for other seasons. It is found that the spatial pattern of SSSanomalyis the most significant in summer and followed by the winter season. The spatial pattern is absent in the summer season.It is found that the spatial pattern of SSS anomaly. The SSS anomalies in the southeastern tropical Indian Ocean are primarily caused by a reduction in precipitation and partly by enhanced evaporation due to increased wind speed whereas negative SSS anomalies in the central-eastern equatorial Indian Ocean are generated by zonal advection anomalies induced by anomalous wind stress, consistent with previous studies. The sub-surface anomalies are caused by wind stress mediated by ocean dynamical processes.ECMWF ORS4 SSS anomaly indicates the null values over AS while in two simulations indicates the only positive values over the AS during JJAS month. During NDJF, there are negative values over the AS that shows the observed model SST was cooler than the SODA SSS.

The model produces the upper ocean circulation features of AS. The currents of upper ocean circulation is compared with SODA reanalysis data from a period of 1999-2008. The main features of the ocean circulation are reasonably simulated in the model. There are strong westward north equatorial currents during NDJF season that being captured in the model with aslight broadening in the meridional direction. The curving of the north equatorial current to east around $6^{\circ} \mathrm{N}$ is also well captured in the model. The coastal currents along the west coast of the Indian peninsula are northward during this time (Shetya, 1986). The western boundary hassouthward flowing Somali Current (Schott \& McCreary, 2001). These coastal circulation patterns are well reproduced in the model and are consistent with the SODA reanalysis data. During summer (JJAS) the Great Whirl is a prominent circulation feature at the Somali coast (Schott \& McCreary, 2001). This feature is captured by the model although the width of Great Whirl is slightly underestimated in the model as compared to the reanalysis data. The west Indian coastal currents are southward during this season with the interior basin circulations eastward feeding to the summer monsoon current. Both the magnitude and direction of the current are well resolved in the model and are comparable with the SODA reanalysis data.

To show the quality of themodel simulation in representing the sub-surface SST characteristics of temperature shown in Figure 9, the latitude-depth plot of temperature at $70^{\circ} \mathrm{E}$ in the AS. The vertical structure of temperature in ROMS simulations are validated against NIOA data for the northern AS. The model is able to capture the vertical structure of temperature. The temperaturenear $150 \mathrm{~m}$ is noted in the simulation, which is well below the mixed layer depth $(\sim 50 \mathrm{~m})$ of this region and does not affect the conclusions. The model captures the layered structure of the upper ocean with correct magnitude very well. The sub-surface temperature structure is very different in the AS. The latitude-depth plot of the 
temperature shows that the thermocline in the AS has a tilted structure with values increasing from south to north.In the AS non-uniform SST warming trend is to continue in the future for both medium and high emission ( Roxy et al., 2020).

The sub-surface SST characteristics of salinityare shown in Figure 10, the latitude-depth plot of salinity at $70^{\circ} \mathrm{E}$ in the AS. The vertical structure of salinity in ROMS simulations are validated against NIOA data for the northern AS. The model is able to capture the vertical structure of sub-surface salinity. The salinity diagram shows that the values are nearly opposite in the AS at higher latitudes. In the region $5^{\circ}-10^{\circ} \mathrm{N}$, where the highest salinity values are observed in the AS. Higher evaporation than precipitation in the northern AS is the principal reason for high salinity in that region. The presence of salty outflow from the Red Sea and the Persian Gulf is also the reason for the high salinity of the region.

\section{Conclusions}

This study examines, th hydrographic property of the Arabian Sea variability using a regional ocean model system (ROMS). Additionally, the effort is also made to investigate the advantage of increasing horizontal resolution. In this regard, two sets of sensitivity experiments are performed using the Regional Ocean Modeling System (ROMS) (version 3.7) with two different horizontal resolutions $1 / 6^{\circ}(\sim 17 \mathrm{~km})$ \& $1 / 4^{\circ}(\sim 25 \mathrm{~km})$. Both simulation followed the same configuration that is customized overAS covering [30E$80 \mathrm{E}, 5 \mathrm{~N}-30 \mathrm{~N}]$ for 10 years. The demonstration both model resolution results with observation and reanalysis data shows a good performance in reproducing thespatial-temporal distribution of surface and subsurface hydrographic property like SST, SSS, SSC, and subsurface temperature and salinity. However, both model shows systmatic bias in terms of magnitude which is slightly reduced in high-resolution simulation. Our simulation shows both the models are capable of producing the annual and seasonal variability hydrographic state however, the high-resolution setup revels better performance both season. The modulation of the latitude-depth profile map simulated by the models shows a reasonable good agreement with respect to NIOA based observation. Though the model simulated surface and subsurface state are well in agreement with the available observation, the amplitude of simulated fields was not in agreement in a few instances for both the setups. However, the disagreement in the case of ROMS-1/ 6 was less than that of ROMS-1/4. The model forcing fields such as a momentum and horizontal gradient of wind stress curl might be responsible for the bias in the model simulated SST (Hackert et al. 2001; Lee et al. 2005). For future studies, the deep diagnosis of source bias would be worth investigating.

\section{Declarations}

\section{Acknowledgements}

Authors thank DST for supporting this work in form of INSPIRE Fellowship. Also thank Tropical Rainfall Measuring Mission (TRMM), ECMWF, and OSCAR respectively for sharing TMI SST, SSS, and SSC datasets for sharing the data used for the analysis. 


\section{Data Availabilty Statement:}

The model data is available with the authors and rest were acknowledged.

\section{References}

Bates NR, Pequignet AC, Sabine CL (2006a) Ocean carbon cycling in the Indian Ocean: 1. Spatiotemporal variability of inorganic carbon and air-sea CO2 gas exchange. Global Biogeochem Cycles 20(3):GB3020. doi:10.1029/2005GB002491

Bates NR, Pequignet AC, Sabine CL (2006b) Ocean carbon cycling in the Indian Ocean: 2. Estimates of net community production. Global Biogeochem Cycles 20(3):GB3021. doi:10.1029/2005GB002492

Beal LM, Molinari RL, Chereskin TK, Robbins PE (2000) Reversing bottom circulation in the Somali basin. Geophys Res Lett 27:2565-2568

Carton JA, Giese BS (2008) A reanalysis of ocean climate using simple ocean data assimilation (soda). Mon Weather Rev 136:2999-3017

da Silva AM, Young CC, Levitus S (1994) Atlas of Surface Marine Data 1994, Volume 1: Algorithms and Procedures. NOAA Atlas NESDIS 6, U.S. Department of Commerce, NOAA, NESDIS

Diansky NA, Zalesny VB, Moshonkin SN et al (2006) High resolution modeling of the monsoon circulation in the Indian Ocean. Oceanology 46(5):608-628. doi:10.1134/S000143700605002X

Donguy JR, Meyers G (1996) Seasonal variation of sea-surface salinity and temperature in the tropical Indian Ocean. Deep Sea Res Part I 43:117-138

Dwivedi S, Mishra AK, Srivastava A (2019) Upper ocean high resolution regional modeling of the Arabian Sea and Bay of Bengal. ActaOceanol Sin 38:32-50. https://doi.org/10.1007/s13131-019-1439-x

George MS, Bertino L, Johannessen OM et al (2010) Validation of a hybrid coordinate ocean model for the Indian Ocean. Journal of Operational Oceanography 3(5):25-38

Hackert EC, Busalacchi AJ, Murtugudde R (2001) A wind comparison study using an ocean general circulation model for the 1997-1998 El Nino. J Geophys Res 106(C2):2345-2362.

doi:10.1029/1999JC000055

Kumar PS, Prasad TG (1999) Formation and spreading of Arabian Sea high salinity water mass. J Geophys Res 104:1455-1464

Lee S-K, Enfield DB, Wang C (2005) Ocean general circulation model sensitivity experiments on the annual cycle of Western hemisphere warm pool. J Geophys Res 110:C09004.

doi:10.1029/2004JC002640 
Locarnini RA, Mishonov AV, Antonv JI, Boyer TP, Garcia HE, Baranova OK,et al.(2013). World ocean atlas 201, Volume 1:Temperature. In S. Levitus Technical Ed., NOAA Atlas NESDIS, 73, pp. 40

Madhupratap M, Prasanna Kumar S, Bhattathiri PMA, Kumar MD, Raghukumar S, Nair KKC, Ramaiah N (1996) Mechanisms of the biological response to winter cooling in the northeastern Arabian Sea. Nature 384:549-552

Masumoto Y, Morioka Y, Sasaki H (2008) High-resolution Indian Ocean simulation-Recent Advances and Issues from OFES. In: Hecht MW, Hasumi H (eds) Ocean Modeling in an Eddying Regime. American Geophysical Union, Washington DC. doi:10.1029/177GM14

Mishra AK, Dwivedi S, Di Sante F (2021a) Performance of the RegCM-MITgcm Coupled Regional Model in Simulating the Indian Summer Monsoon Rainfall. Pure ApplGeophys. https://doi.org/10.1007/s00024020-02648-0

Mishra AK, Kumar P, Dubey AK et al (2021b) Impact of horizontal resolution on monsoon precipitation for CORDEX-South Asia: A regional earth system model assessment. Atmos Res 259:105681. https://doi.org/10.1016/j.atmosres.2021.105681

Momin IM, Mitra AK, Mahapatra DK et al (2014) Impact of model resolutions on Indian Ocean simulations from Global NEMO Ocean Model. Indian Journal of Geo-Marine Science 43(9):1667-1674

Neema CP, Hareeshkumar PV, Babu CA (2012) Characteristics of Arabian Sea mini warm pool and Indian summer monsoon. Clim Dyn 38:2073-2087

Prasad TG, Ikeda M (2002a) The winter-time watermass formation in the northern Arabian Sea: A model study. J Phys Oceanogr 32:1028-1040

Prasad TG, Ikeda M (2002b) A numerical study of the seasonal of Arabian Sea high-salinity water. J Geophys Res 107(C11):3197. doi:10.1029/2001JC001139

Rao RR, Sivakumar R (2000) Seasonal variability of near-surface thermal structure and heat budget of the mixed layer of the tropical Indian Ocean from a new global ocean temperature climatology. J Geophys Res 105:995-1015

Sharma R, Mankad B, Agarwal N et al (2012) An assessment of two different satellite-derived precipitation products in relation to simulation of sea surface salinity in the tropical. Indian Ocean Journal of Geophysical Reasearch 117(C7):C07001. doi:10.1029/2012JC008078

Shchepetkin AF, McWilliams JC (2003) A method for computing horizontal pressure gradient force in an oceanic model with a nonaligned vertical coordinate. J Geophys Res 108(C3):3090. http://dx.doi.org/10.1029/2001JC001047 
Shchepetkin AF, McWilliams JC (2005) The regional oceanic modeling system: a split-explicit, freesurface, topography-following-coordinate ocean model. Ocean Modeling 9:347-404

Shenoi SSC, Shankar D, Shetye SR (2002) Difference in heat budgets of the near-surface Arabian Sea and Bay of Bengal: implications for the summer monsoon. Journal of Geophysical Rsearch- Oceans 107(C6):5-1

Shetye S (1986) A model study of the Arabian Sea temperature. J Mar Res 44:521-542

Stramma S, Brandt P, Schott F. Quadfasel D, Fisher J (2002) Winter and summer monsoon water mass, heat and freshwater transport changes in the Arabian Sea near $8^{\circ} \mathrm{N}$. Deep Sea Res Part II 49:1173-1195

Tomczak M, Godfrey JS (1994) Regional Oceanography: An Introduction. Elsevier Science Inc., Tarrytown Vinayachandran PN, Shetye SR, Sengupta D et al (1996) Forcing mechanisms of the Bay of Bengal circulation. Curr Sci 71:753-763

Wang Yu, Peng L, Li Tianyi, et al (2011) Climatologic comparison of HadISST1 and TMI sea surface temperature datasets. Science China Earth Science 54(8):1238-1247. doi:10.1007/s11430-011-4214-1

\section{Figures}




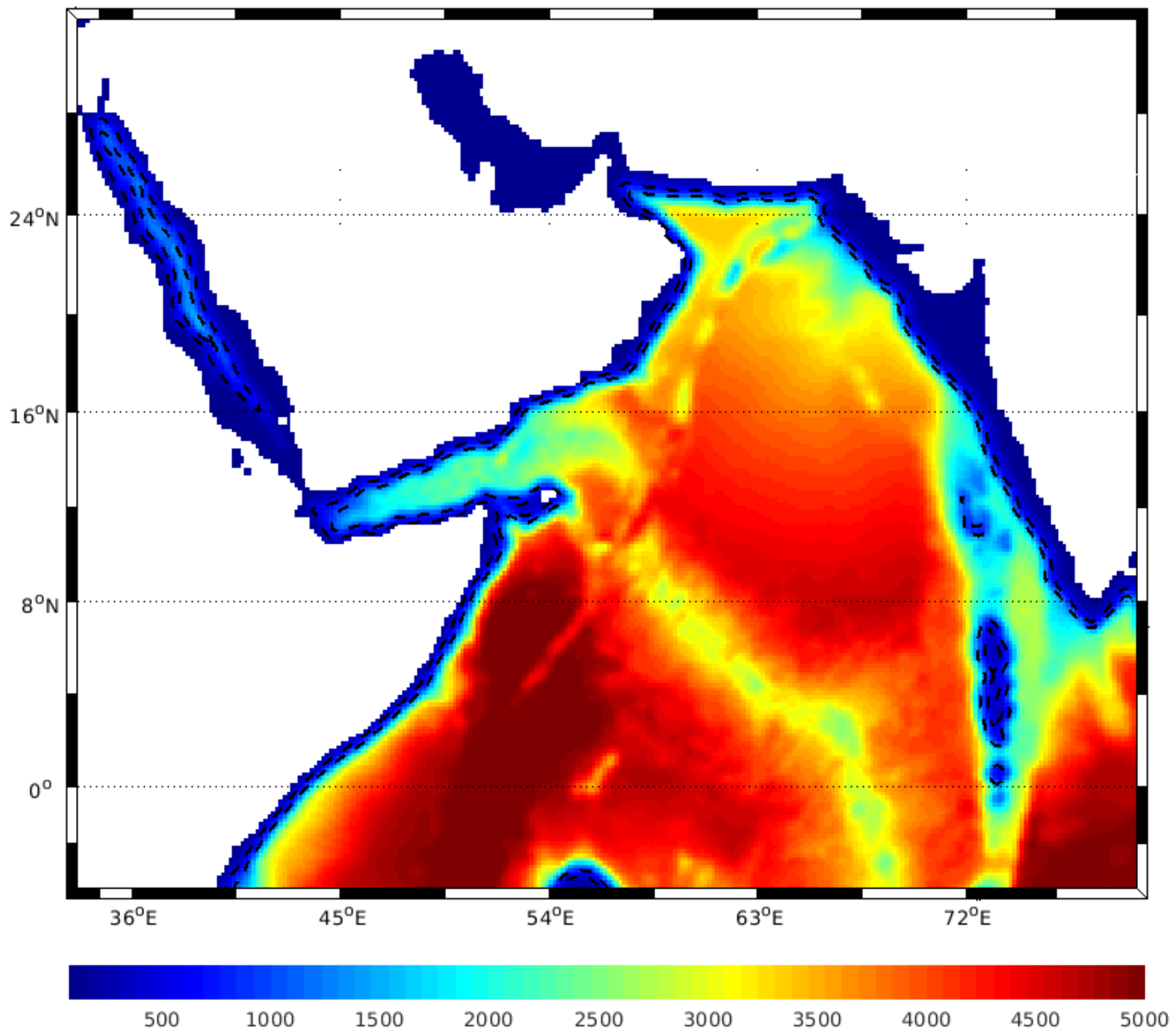

Figure 1

Bathymetry of the model domain 

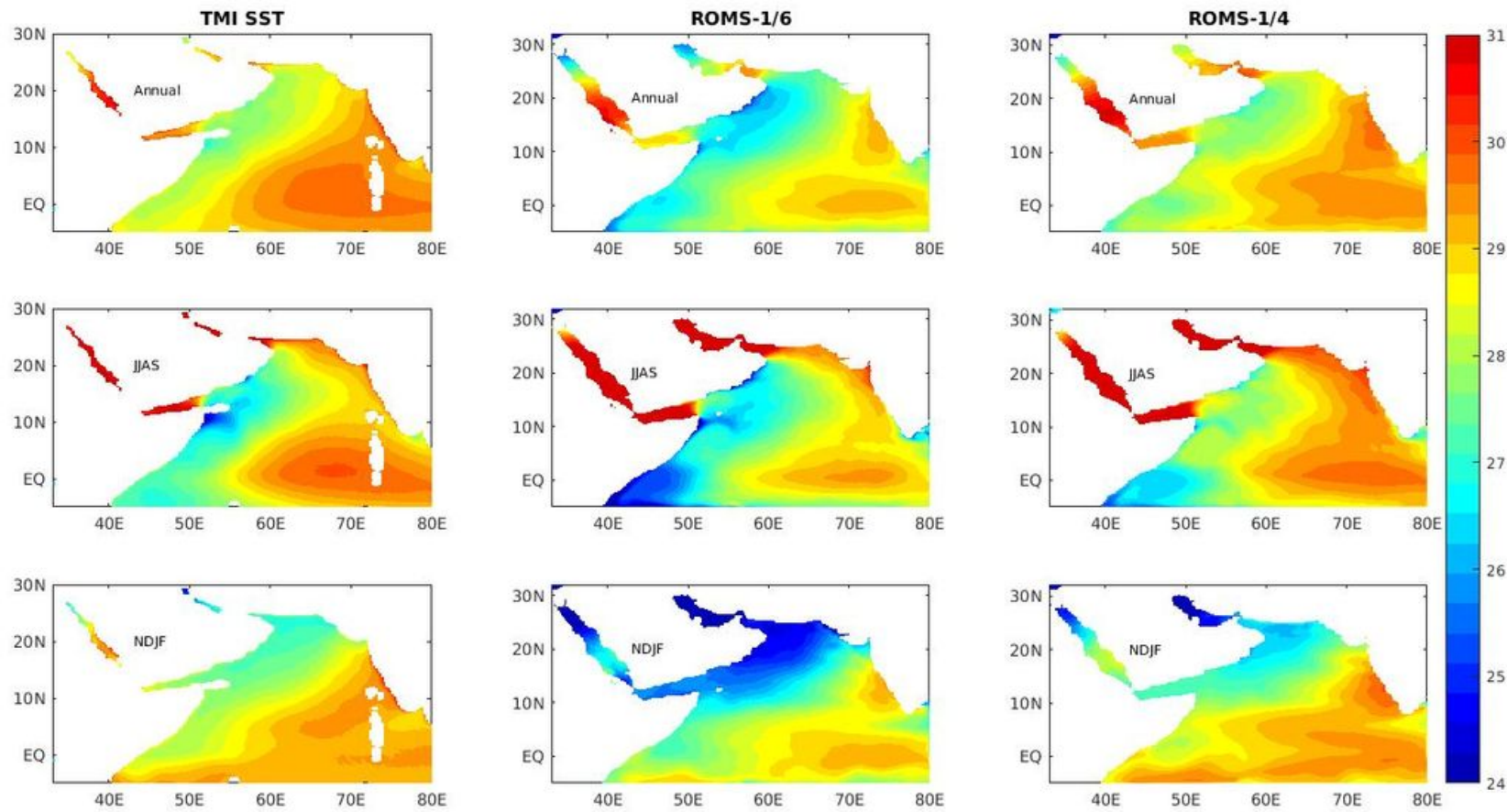

Figure 2

Climatology (10 years) of seasonal composite of SST $\left({ }^{\circ} \mathrm{C}\right)$ during Annual (first row), June-September (second row), November-February (third row) obtained from ROMS-1/4 (left panel), ROMS-1/6 (middle panel) and TMI-SST dataset during 1998-2014 (right panel)
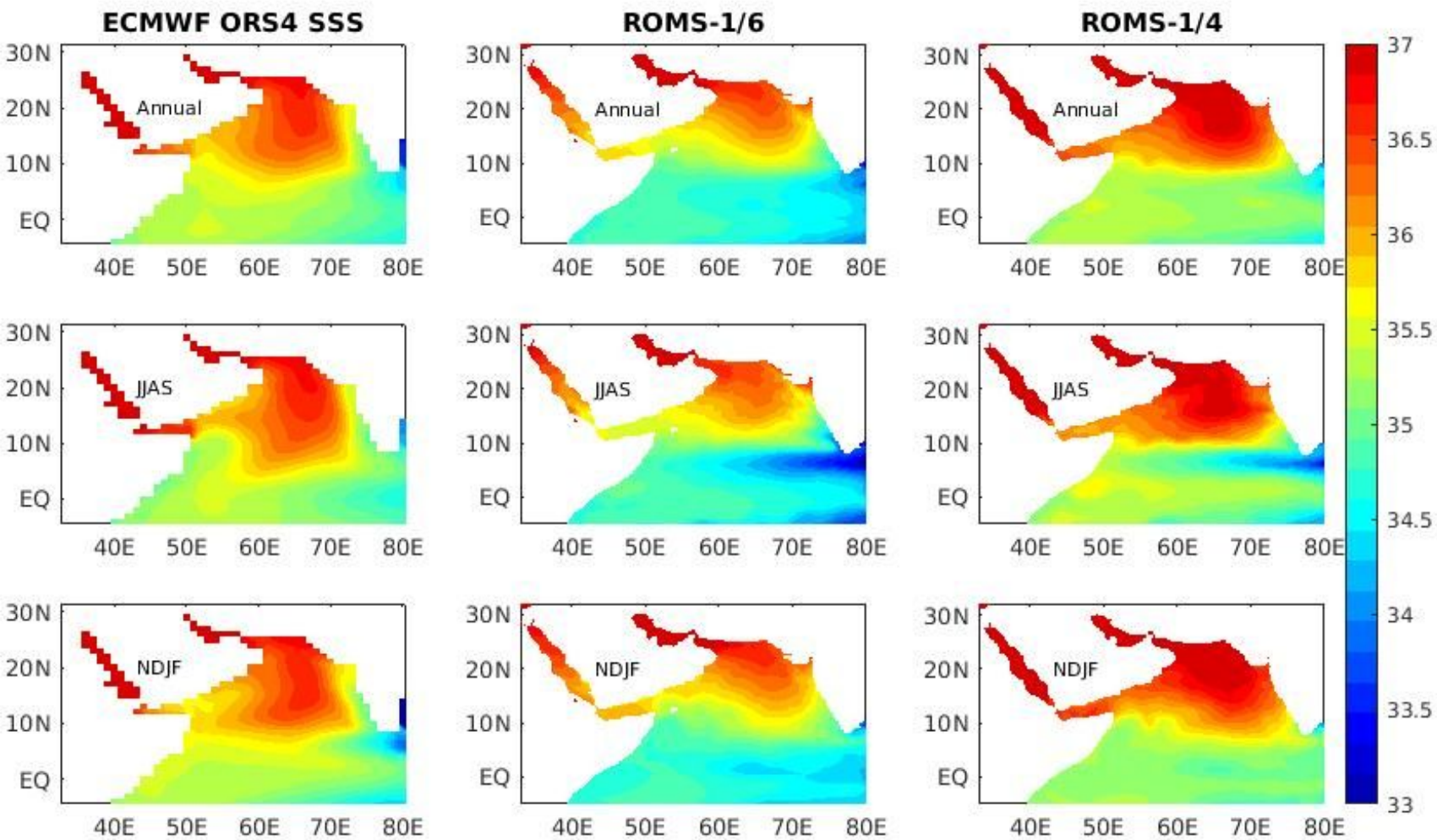
Figure 3

Climatology (10 years) of seasonal composite of Salinity (PSU) during Annual (first row), JuneSeptember (second row), November-February (third row) obtained from ROMS-1/4 (left panel), ROMS-1/6 (middle panel) and ECMWF-ORS4 dataset during (1999-2008) (right panel)
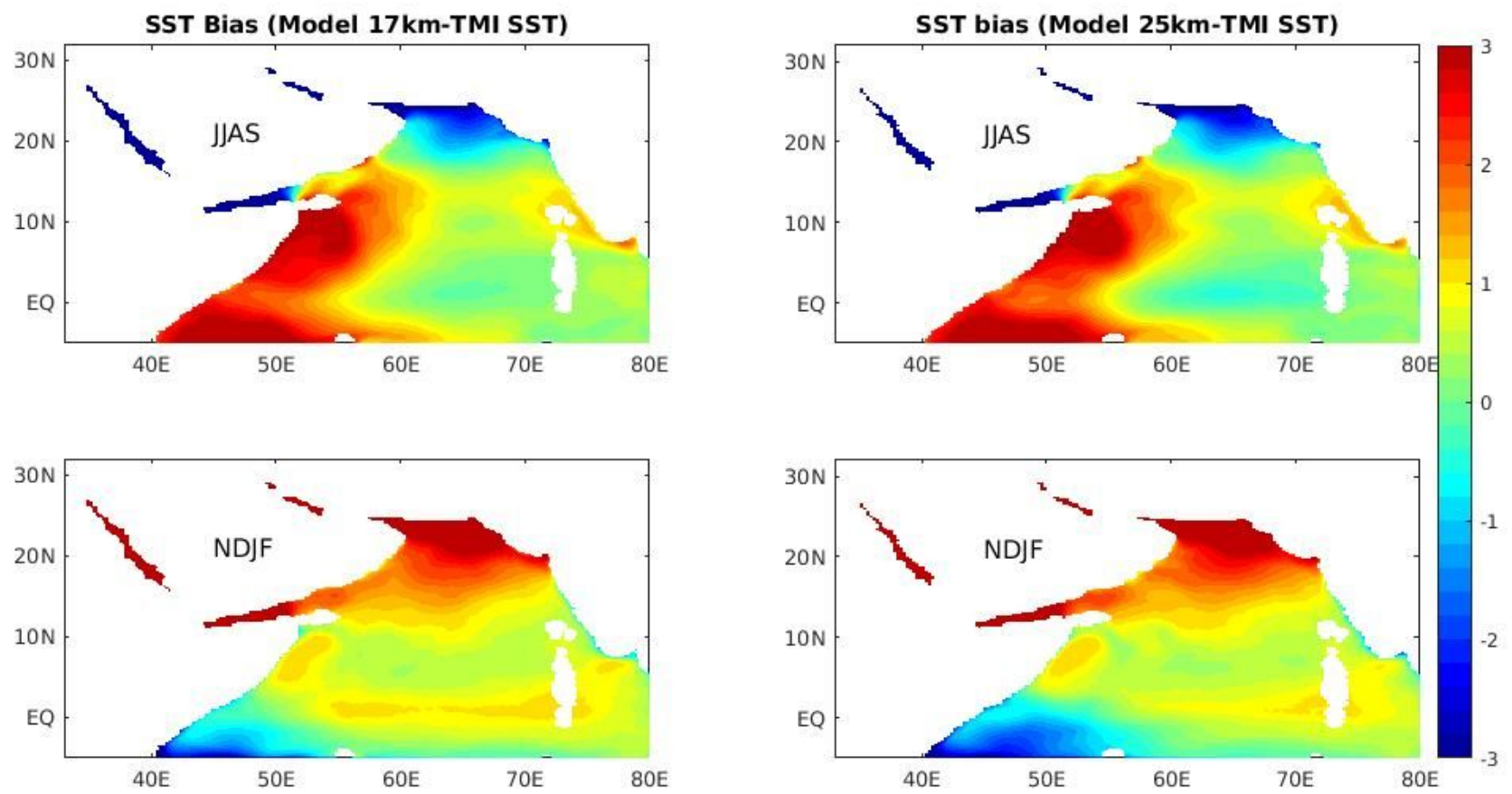

\section{Figure 4}

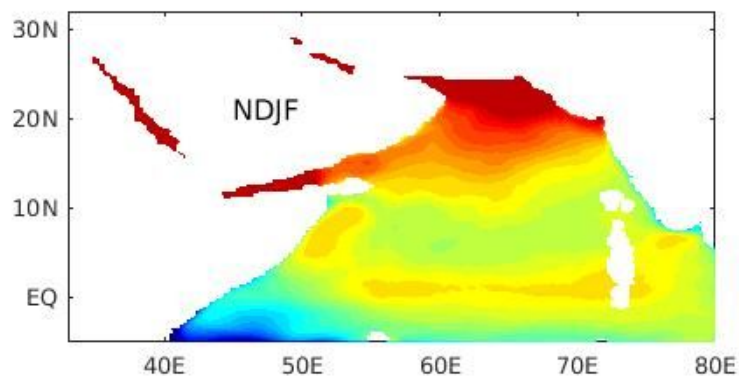

SST Bias between Model and TMI SST for JJAS month (upper panel); SST Bias between Model and TMI SST for NDJF month (lower panel) 

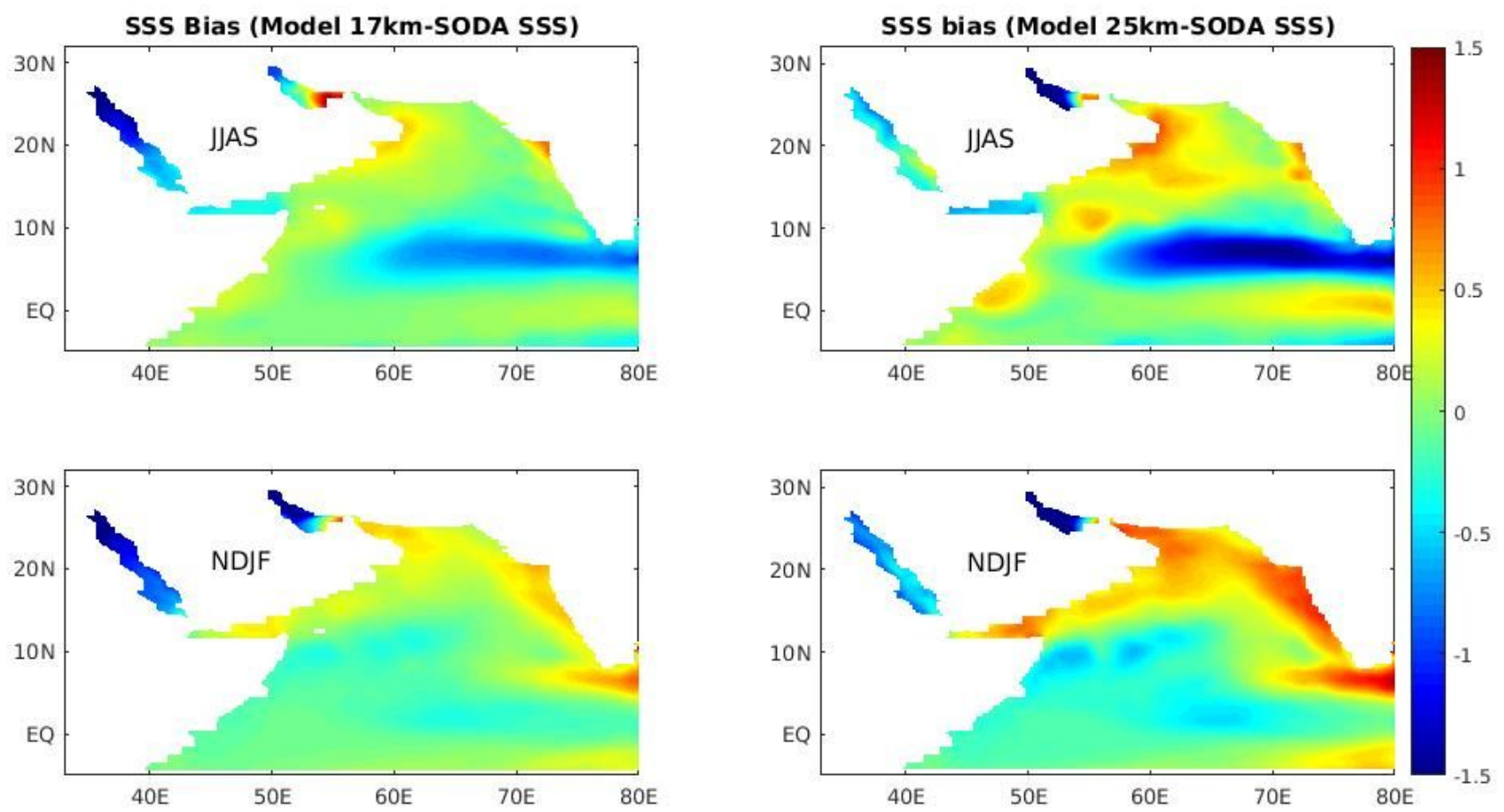

Figure 5

SSS Bias between Model and SODA SSS for JJAS month (upper panel); SSS Bias between Model and SODA SSS for NDJF month (lower panel)
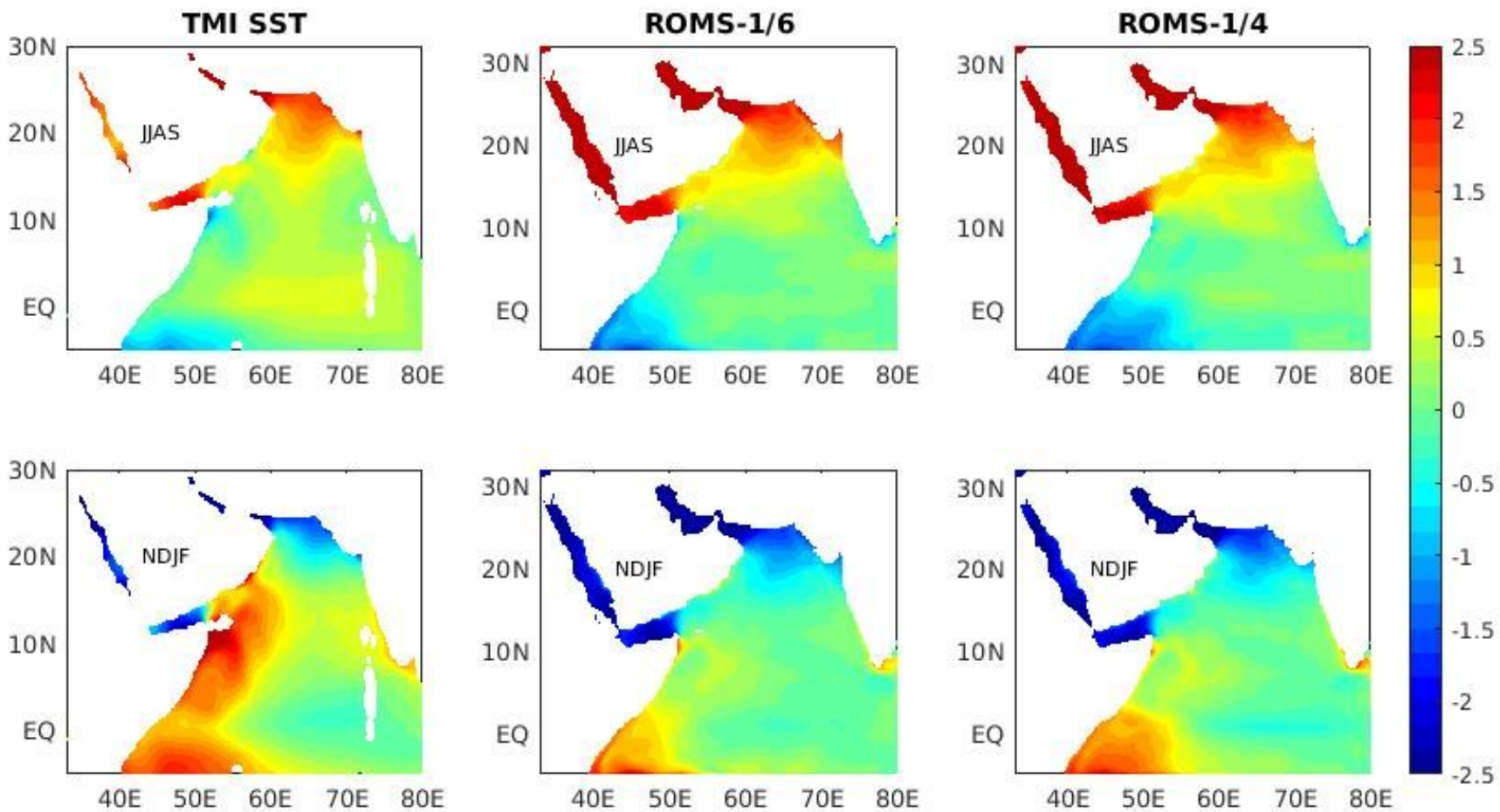

Figure 6 
SST anomaly for JJAS month (upper panel); SST anomaly for NDJF month (lower panel)
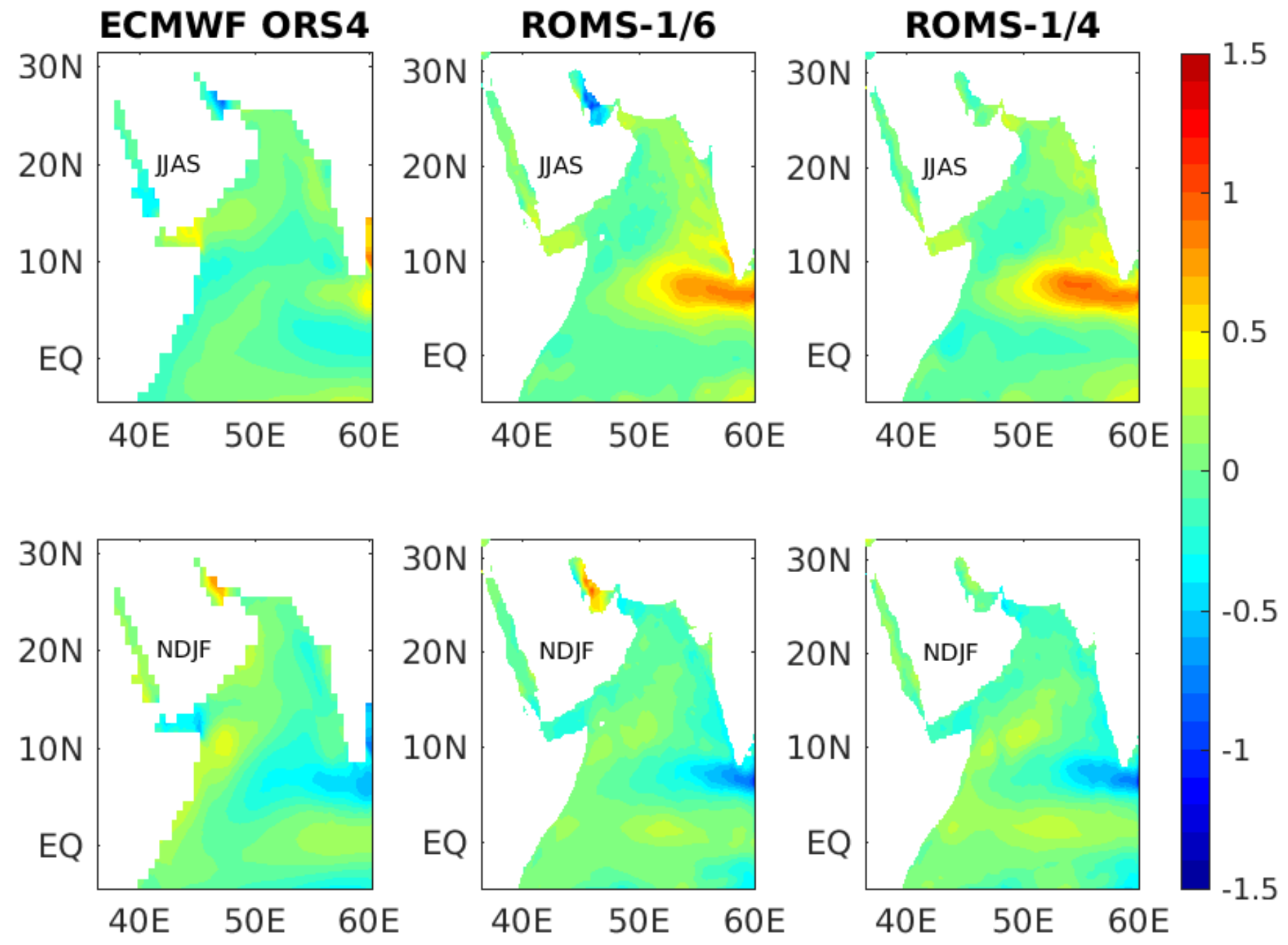

Figure 7

SSS Anomaly for JJAS month (upper panel); SSS anomaly for NDJF month (lower panel) 

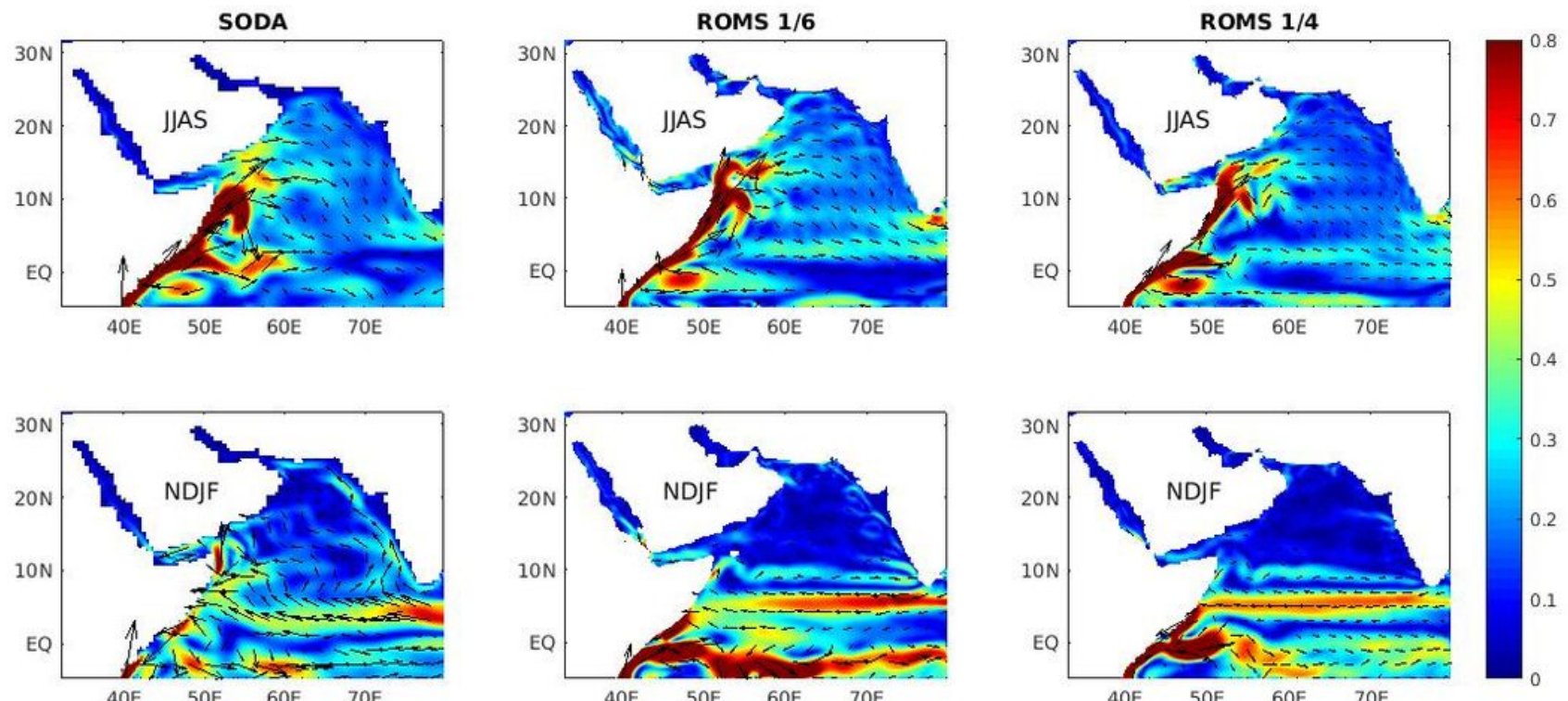

\section{Figure 8}

Climatology (10 years) of theseasonal composite of Surface currents $(\mathrm{m} / \mathrm{s})$ during June-September (first row), November-February (second row) obtained from ROMS-1/4 (left panel), ROMS-1/6 (middle panel), and SODA dataset during (1999-2008) (right panel). Color shading denotes wind speed. 


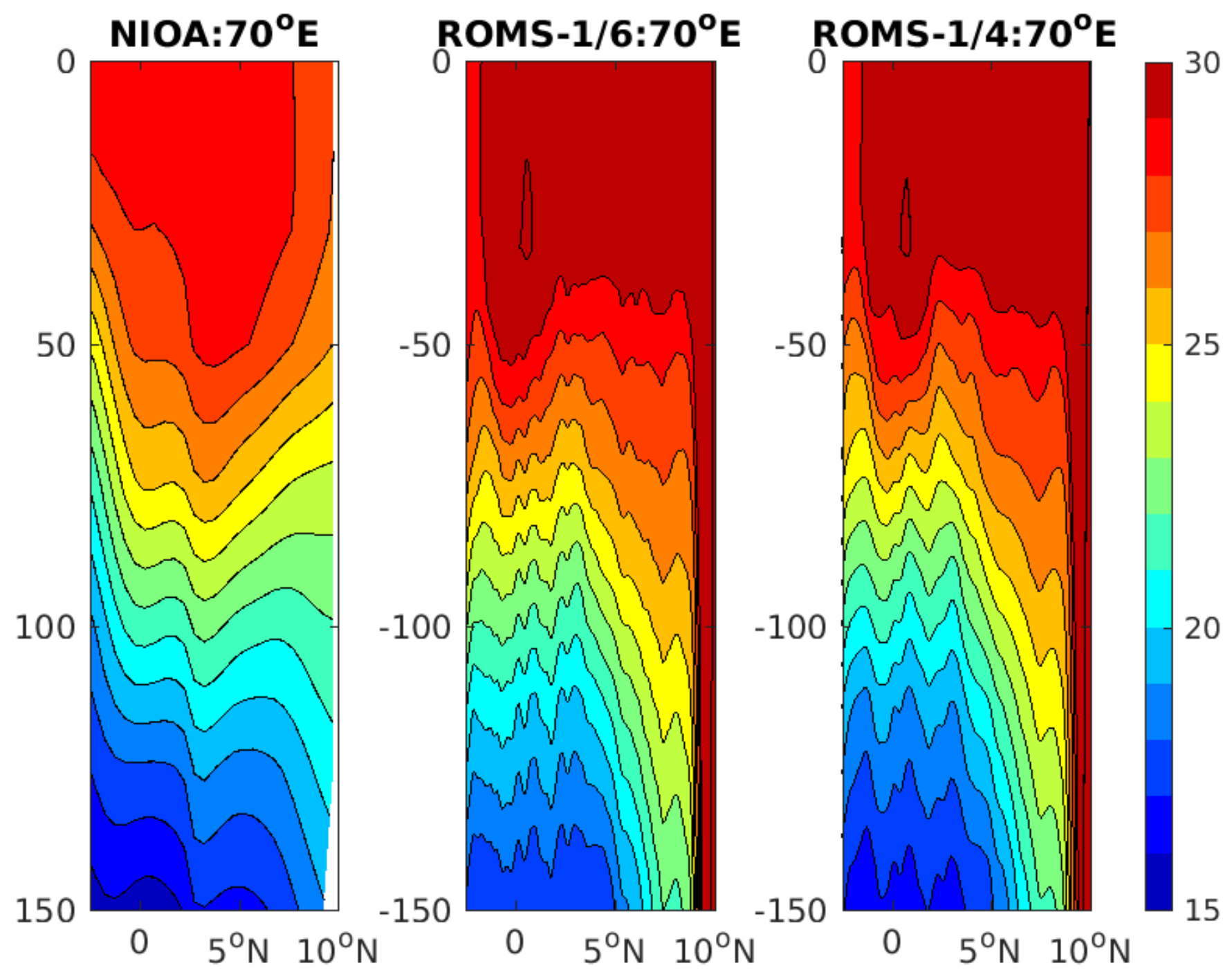

Figure 9

The latitude-depth plot of temperature at $70^{\circ} \mathrm{E}$. The model temperature values are compared with the corresponding NIOA values. 

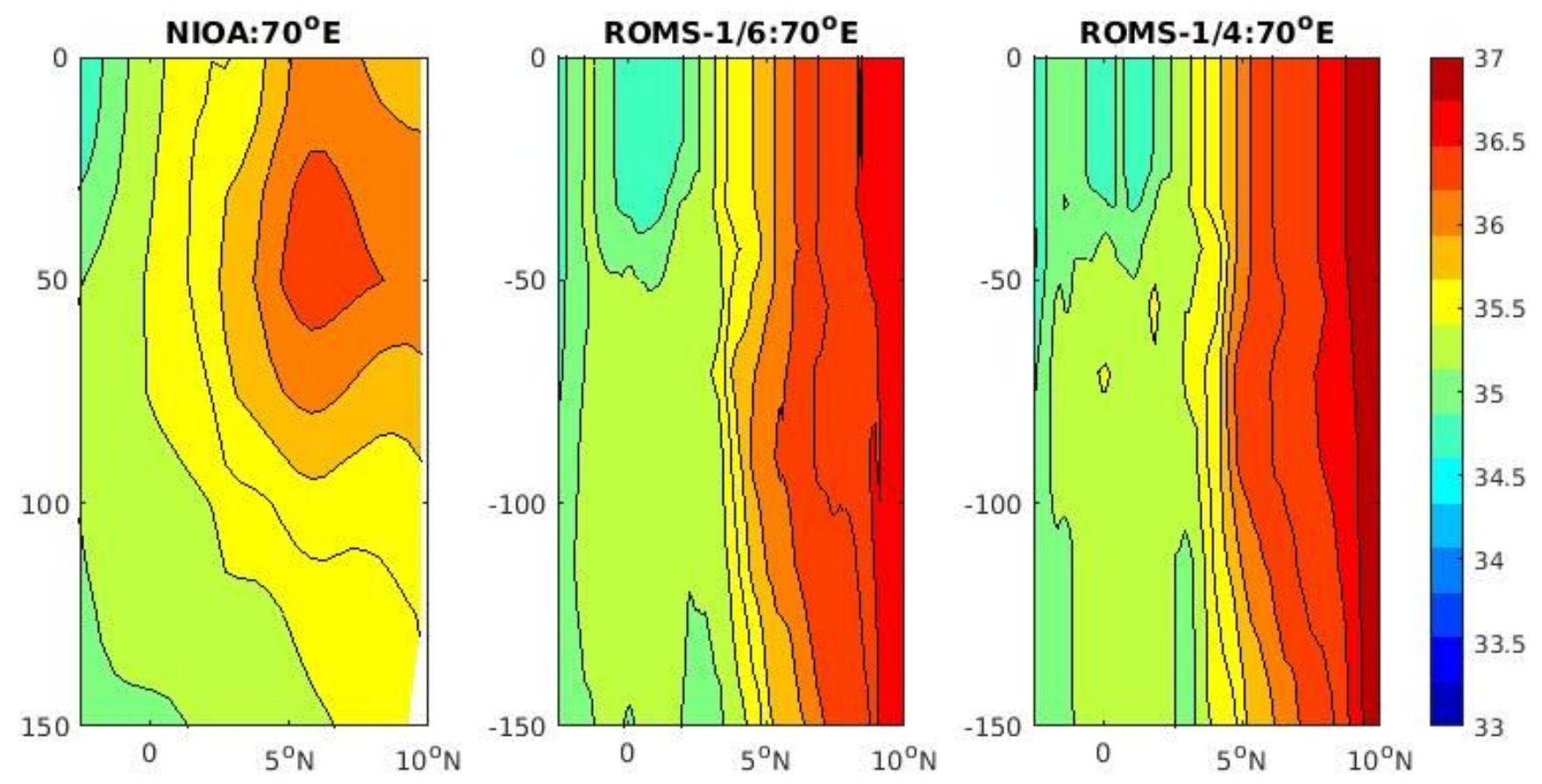

Figure 10

The latitude-depth plot of salinity at $70^{\circ} \mathrm{E}$. The model salinity values are compared with the corresponding NIOA values. 